\title{
Dewey and Political Communication in the Age of Mediation
}

\author{
Lance E. Mason* \\ Indiana University - Kokomo \\ *Corresponding Author: Lanmason@iuk.edu \\ Received : 2019-09-24 \\ Revision : 2019-11-17 \\ Accepted : 2019-11-27
}

How to cite this paper: Mason, L. E. (2019). Dewey and political communication in the age of mediation. Journal of Culture and Values in Education, 2(3), 94-102.

\section{Abstract}

The present sociopolitical environment in the United States is perpetually mediated and beset with information from innumerable sources. This paper argues that Dewey's conception of communication as a mutual act of meaning-making holds insights for explaining the connections between pervasive mediation and political polarization, in addition to understanding why political discourse has become more degrading in recent years. It also points the way toward viable solutions by arguing for the reorientation of schools toward valuable living experiences that are becoming less pronounced in the broader culture, such as sustained face-to-face engagement on matters of social import.

Keywords: Pragmatism, Democratic Education, Media Literacy, Media Ecology

\section{Introduction}

The aim of this paper is to employ Dewey's conception of communication derived from Experience and Nature (1924/1958) and applied to the public domain in The Public and its Problems (1927/1946) and other later political works in an analysis of contemporary democratic communication and how it can be improved. Dewey offered continued social commentary and analyses throughout the formative years of mass media (radio and television), providing unique insight into the relationships between media and democracy that can inform present discourse on media and its democratic implications. In the later part of Dewey's career, he became a public intellectual engaged in many of the most important issues of the early $20^{\text {th }}$ century. Dewey's social and political theories provide a way of thinking about the relationships between individuals and society that offer unique insight into the possibilities of sustaining a democratic polity under current societal dynamics.

The present sociopolitical environment in the United States is perpetually mediated and beset with information from innumerable sources. Research demonstrates, for example, that teens now spend over nine hours per day with media outside of school and homework (Pew Research Center, 2018), and media use among adults is around 12 hours per day (eMarketer, 2016). The 
use of mobile devices and social media has changed how many people receive media and has increased both the volume and speed at which people can be exposed to political stories. Building upon previous work (Mason, 2016, 2017), this paper argues that, in this contemporary sociopolitical milieu, Dewey's conception of communication as a mutual act of meaning-making holds insights for explaining why U.S. culture has become far more polarized and why political discourse is degrading. It also points the way toward viable solutions.

\section{Background}

Walter Lippmann (1922/2010, 1925/1993), often called the father of media studies, emerged after World War I with a pessimistic view of the possibilities of people-centered democracy. While movements for stronger forms of democracy had grown throughout the Progressive Era in the early $20^{\text {th }}$ century, WWI had at least temporarily halted their momentum. After the war, the radio grew quickly as a mass medium of communication and added to the power to influence public opinion already wielded by newspapers. While working for the War Department and State Department during the war, Lippmann was able to witness, from the inside, how government agencies worked in concert with news agencies to create support for what was initially an unpopular war.

Lippmann's critiques of the limits of democracy were powerful and influential. Dewey called Lippmann's 1922 book Public Opinion "perhaps the most effective indictment of democracy as currently conceived ever penned" (1922/1983, p. 337). Dewey (1924/1958) argued that Lippmann's proposals, which focused on distributing power through various groups of experts that would work on matters that they most directly understood, would offer improvements to the existing state of affairs. However, Dewey believed a more vigorous dissemination of decision-making was needed. To understand why, one must consider how Dewey believed humans derive meaning from their experiences.

In Experience and Nature (1924/1958), Dewey identifies the communication-centric nature of mind, knowledge, and learning. He explains:

"Because of converse, social give and take, various organic attitudes become an assemblage of persons engaged in converse, conferring with one another, exchanging distinctive experiences, listening to one another, over-hearing unwelcome remarks, accusing and excusing. Through speech a person dramatically identifies himself with potential acts and deeds; he plays many roles, not in successive stages of life but in a contemporaneously enacted drama. Thus mind emerges" (p. 170).

Dewey asserts that people do not become social as they grow. Rather, social interaction is innate among humans and is a central factor in growth and learning. The very conception of mind, from this perspective, is an emergent feature of continuous interaction, from which individuals begin to differentiate themselves from the world around them through social communication. This process is never complete, as such interactions continue to influence people throughout their lifespan. Dewey's conception offers a direct critique to the prevailing 
liberal conception of self and mind that still persists in popular assumptions. These assumptions also underpin our institutions, including how media is structured.

For present purposes, what is crucial to understand is that for Dewey, the full import of these communicative environments necessarily involves direct, unencumbered communication between people. This is because for Dewey, meaning is not something acquired in an isolated mind, it is something that is actively made in communication, within the act itself. Dewey states:

"The heart of language is not 'expression' of something antecedent, much less expression of antecedent though. It is communication; the establishment of cooperation in an activity in which there are partners, and in which the activity of each is modified and regulated by partnership. To fail to understand is to fail to come into agreement in action.... Meaning is not indeed a psychic existence; it is primarily a property of behavior, and secondarily a property of objects. But the behavior of which it is a quality is a distinctive behavior; cooperative, in that response to another's act involves contemporaneous response to a thing as entering into the other's behavior, as this upon both sides" (1924/1958, p. 179).

In this conception, meaning is not acquired in a manner analogous to a pipeline transferring materials between locations. Rather, meaning must be actively made by participants within the process of communication. Thus, the quality and variety of communication environments will have effects on the orientation of individuals, groups, and ultimately how discourse is both perceived and pursued. From this perspective, the particular character of democracy is an emergent feature derived from these environments, a conclusion that Dewey decidedly offers in The Public and its Problems (1927/1946).

Dewey's "Great Community" envisions a world in which people are grounded by direct participation in local matters that would provide them with first-hand political experience that would minimize manipulation by what Walter Lippmann (1922/2010) called the "stereotypes" of media. By comparison, people today are largely connected to distant others electronically while often having little substantive communication with those in immediate physical proximity. Both Dewey and Lippmann understood that mediated social interactions that lack direct contextual experience foster a more easily manipulated population, but the implication of Dewey's theory of communication is that online interactions like those generally experienced in social media offer impoverished communicative experiences that will necessarily result in diminished understandings of social and political events. In such contexts, it becomes easier to fall victim to manipulation by vested interests and to demonize others because one is not engaging fully with the other. In a perpetually mediated culture with severely diminished direct engagement, vilifying the other becomes easy.

\section{Change in Media}

To understand present challenges, more must be said about media environments. Fast-forward from Dewey's time to the present day: There are vastly expanded media choices and platforms, making the media landscape much more difficult to navigate for individual citizens and leaving 
society without a sense of commonality. Specialization and expertise have grown significantly, seemingly in a manner analogous to that advocated by Lippmann. However, society appears to have reached another crisis of democracy similar to that encountered by Dewey and Lippmann roughly a century ago. Trust in media is at a 40-year low (Gallup, 2016) and has waned in step with a general decline in trust of public institutions. The expert model, as least it has been enacted, appears to be failure.

The decline in public trust in media is directly related to changes in the media landscape. The emergence of CNN in 1980 and its early decision to feature oppositional talking heads became the norm for cable news (Taibbi, 2019), teaching viewers to see social issues in binary terms that can be adjudicated in a manner analogous to a prize fight. This was exemplified by CNN's long-running hit show Crossfire, which was soon replicated by subsequent cable news outlets and network news. This alteration of political discourse began, however, when political debates were first televised, long before the advent of cable news. Networks, in an attempt to bolster the interest in candidates talking about dry policy positions, began covering these events under the guiding metaphor of a boxing match, with an emphasis on gaffs and one-liners, to the detriment of substantive consequential analysis.

The medium of television was instrumental in this combative turn. As a medium, screens favor action, and media theorists have long noted that television news gives more coverage to events that are visually appealing when compared with print (Hart, 1994; Postman \& Powers, 2008). The public pedagogy of the screen teaches that what is newsworthy is dramatic and incendiary. In an age of ubiquitous screens, should we be surprised, then, when a fast-talking, one-linedropping con man becomes president?

New media technologies, including the Internet and social media, have increased the volume of news while also facilitating niche marketing on an unprecedented scale, adding to a businessdriven process of market segmentation that became more prevalent in the late $20^{\text {th }}$ century. The new media environments often present ideologically bifurcated readers and viewers with entirely different universes of discourse, fueling political polarization. Newspapers, in response to shrinking add revenue due to pressures from diminished sales because of Internet competition, have either closed or contracted, leading to diminishing local news reporting, less in-depth reporting, and a greater likelihood of reporting factual errors or passing along public relations material as news without thoroughly vetting it for bias or inaccuracies. Newspapers increasingly depend on Internet ad revenue, leading to heightened pressure for headlines or stories that are hyperbolic or sensationalistic. Such stories are more likely to generate clicks and thus contribute to the company's bottom line.

In the public domain, new media technologies have facilitated collective action from likeminded individuals, bolstering justice-oriented political movements such as Black Lives Matter and the \#MeToo movement. Yet, simultaneously, new media has made communication across differences more difficult as citizens have become normalized to political information segmented into pre-formed ideological enclaves. The personalization of social media now allows an individually tailored, algorithmically curated media experience that decreases the 
likelihood that one will be exposed to ideas that might contradict one's opinions. The profit motive of social media bakes increasing attention into its design. If people are given more material that they like, they will visit the platform more often and stay longer, leading to increased advertising revenue for the company (Alter, 2018).

Due to media consolidation, financial pressures from new media, and lax enforcement of FCC regulations, legacy media (print, radio, and television) have also contributed to separating viewers into ideological camps by treating political positions as catered demographics. This has clearly made it difficult for citizens to find common political ground. This, in combination with a relentless 40 -year-long ideological war waged by the political right, has birthed consequences that have contributed to the emergence of nationalistic movements and other forms of social unrest in both the U.S. and Europe. In addition, a move toward "neutral" - as opposed to objective-news coverage has created immense confusion for news consumers. The term "objective" here is intended as Lippmann understood it, described as "practicing the scientific virtues of weighing the credibility of statements, applying probability and considering the quantitative importance of particular facts" (Jansen, 2012, p. 91). For example, in the late $20^{\text {th }}$ century and continuing today, many of the most pressing societal problems such as climate change, smoking, and the dangers of toxic pollution have scientific evidence that suggests clear action. A standard of objectivity would lead news outlets to report the results of science, but on these issues and many others, major new organizations followed the standard of neutrality and continually reported them as public debates. The work of Oreskes and Conway (2010) traces many of the agitators of these issues to moneyed interests such as industry groups and think tanks simultaneously funding other attacks on the public sphere in a movement known as neoliberalism. However, for our purposes, it is crucial to note the move by our profit-driven media to report crucial public matters in a way that serves their advertisers over the public.

Recent media developments have exposed the lax standards of journalism that have come to pervade mainstream media in the neoliberal era. The Russiagate fiasco, including the willingness to report innuendo and speculation, to make sweeping generalizations, and to draw conclusions without sufficient evidence, has laid bare the inability of the media to be source of cohesion and meaning-making for the public. While copious news time was devoted to every angle on the Russiagate conspiracy theory, comparatively little coverage has been given to the treatment of Julian Assange or the recent reimprisonment of Chelsea Manning, events that portend potentially genuine threats to freedom of the press.

If Russiagate had merely been an aberration, this concern could potentially be dismissed. Unfortunately, the shoddy, unethical reporting seems to be emblematic of a larger trend toward disregarding evidence in order to craft a preferred narrative. One need only look at recent news coverage of the turmoil in Venezuela to demonstrate this. Media outlets, even respected organizations like NPR, report the U.S. government narrative about Venezuelan President Nicolas Maduro being a brutal dictator, but this is at least partially contradicted by the fact that the CIA's chosen Interim-President, Juan Guaido, is able to host open rallies that call for government overthrow in the capital and other large cities, despite the fact that the Venezuelan army has remained loyal to Maduro. 
NPR has recently provided extended reporting on the refugees who are fleeing Venezuela to Columbia and other neighboring countries, yet they fail to mention that the primary cause of the refugee crisis is the U.S. economic sanctions imposed on Venezuela. The U.S. government narrative that the crisis has been caused by Venezuelan government ineptitude goes unchallenged, as does the rationale for yet another U.S. overthrow of a South American government. These instances demonstrate that, while giving citizens information, the media do not place it in the proper context that will afford intelligent opinion and potentially prompt citizens to pressure politicians to act in different ways.

\section{What to Do}

In the late 1920s, Dewey became increasingly concerned about the control of business, what he called the "pecuniary interests" (1930/1999) over the media and the newly emerging commercial culture. Dewey's solution was to "socialize intelligence" (1939/1989). While he took pains to distinguish his suggestions from the prevailing strain of socialism during that time and he offered no direct prescriptions, one can imagine an intelligence response to the aforementioned challenges consisting of the passage of new public interest laws for media, labeling social media as public utilities so they could be more tightly regulated for the common good.

A pragmatist's perspective leaves room for practical solutions such as improving algorithms and technologies, but this could at best be only part of the answer. A substantive grappling with these challenges also requires recognizing the implications of Dewey's social and communicative conception of thought and mind for the Internet and social media. For example, social media is currently a great way for otherwise insular individuals to find others with common interests; however, these groups often can and do remain insular, creating echo chambers that dampen their understandings of broader affairs and further contributing to the aforementioned phenomena of polarization. In Dewey's conception of the "Great Community," it is a precondition that "different groups interact flexibly and fully in connection with other groups" (1927/1946, p. 147). This could conceivably be improved by changing the ways people use social media, but such environments would also have to be countered by countervailing practices in both the public and in educational institutions. In Dewey's conception, substantive communication has the potential, if properly fostered, to disrupt differences and allow divided groups to achieve common action toward positive social change, and this must necessarily be found, to a large extent, outside the bounds of mediated communication.

A clear reckoning with present challenges must also lead us to consider the possibility that even if we manage to vastly improve the content coverage of media, the disjointed nature of the Internet and social media may simply be incompatible with the meaning-making functions needed to power a thriving democratic culture. Dewey (1927/1946) reminds us that:

"meaning depends upon relation to what it imports, to what its social consequences are. This import cannot be determined unless the new is placed in relation to the old, to what has 
happened and been integrated into the course of events. Without coordination and consecutiveness, events are not events, but mere occurrences, intrusions; an event implies that out of which a happening proceeds. Hence if we discount the influence of private interests in procuring suppression, secrecy, and misrepresentation, we have here an explanation of the triviality and 'sensational' quality of so much of what passes as news" (p. 180).

Needless to say, the circumstances described by Dewey have become vastly more pronounced in new media environments. As long as profit is the singular driving motive of media companies, they will be compelled to emphasize drama, scandal, and sensationalism despite the otherwise good intentions of reporters and editors. This leaves the question of whether education can offer an adequate response to these societal challenges.

\section{How Should Education Respond?}

Dewey (1916/2009) argued that you must figure out the kind of society you want to create before considering your education system. Presently, our education system speeds students along in a culture of diminished contextual meaning-making. Spend any significant amount of time in, say, an average elementary school setting, and you are likely to witness students with electronic devices working in isolation on "teacher-proof" activities created by computer programmers. Many have criticized the attempt to diminish the status of teachers through scripted curricula and the standardization movement that is often the impetus, yet far fewer have openly criticized the digital devices that perfect the ability to implement canned lessons and collect data. If so much of our electronic culture is user-friendly, what are the arguments for immersing young students in it? If the culture is lacking the personal connections that add context that can cut through the stereotypic representations that pervade the media, why is cultivating these relationships not one of our primary educational goals? If our political culture is disintegrating, why is social studies not our main subject of concern for students?

At present, schools expend much of their energy replicating the problematic biases of the larger culture, emphasizing speed and a narrow conception of performance over substance and depth. While schools cannot singlehandedly steady our cultural imbalances, they could be intelligently directed at ameliorating these problems. To do so, we must have a sober conversation about the role of media technologies in a democracy, and Dewey's conceptions provide a sound avenue for such a reconsideration.

Among many potential avenues for change, Dewey's analysis suggests that "slow schools" should perhaps be more of a focus. In addition, media literacy as it is currently conceptualized teaches students to investigate meaning and bias in media messages, and in its more robust forms to examine how media production techniques influence perception and understanding. These are important skills to make universal, certainly, but in order to substantively address the perpetually mediated and commodified social environment of new media, education needs to take a broader view. This suggests a few directions for expanding medial literacy education. First, new media environments should become the subject of inquiry. How does social media change our relationships with one another? How does it change how we see ourselves and our 
society? Citizens that are literate about new media need to consider these questions. Second, schools must lead students toward a deeper interrogation of the rhetorical purposes of language. Students need to be able to recognize techniques of rhetorical manipulation in both written and spoken forms. Third, students should be given ample time to talk through complex social issues with one another. The school is an obvious place to begin a reclamation of direct, face-to-face interaction about matters of social import. What once might have been considered implicitly acquired skills in direct exchanges with others, now, with environments that are so pervasively mediated by technologies, these same abilities must be explicitly taught and practiced. Lastly, educators must come to see the connection between pervasive technologies in the broader culture and the drive for standardization in schools. The world of the algorithm is also the world of the standardized test. It is an imagined world of manipulation and control by code and numbers. Educators must come to recognize the dangers of what Dewey called the "quantification of life" that produces "intellectual and moral mediocrity" (1930/1999, p. 12), which subsequently leaves students in the position to be manipulated by profit-driven corporations. As an alternative, educators must fight to create spaces of intellectual freedom for students that allow them to push back against both pervasive mediation and the commodified culture that created it, instead imagining alternative ways of living and being. 
Mason, L. E. (2019). Dewey and Political Communication in the Age of Mediation

\section{References}

Alter, A. (2018). Irresistible: The rise of addictive technology and the business of keeping us hooked. New York, NY: Penguin Books.

Dewey, J. (1916/2009). Democracy and education. Greensboro, NC: WLC Books.

Dewey, J. (1922/1983). Review of Public Opinion by Walter Lippmann. In J. A. Boydston (Ed.), The collected works of John Dewey, 1882-1953: The middle works, volume 13: 1921-1922 (pp. 337-344). Carbondale and Edwardsville, IL: Southern Illinois University Press.

Dewey, J. (1924/1958). Experience and nature. Mineola, NY: Dover Publications, Inc. Dewey, J. (1927/1946). The public and its problems. Athens, OH: Swallow Press Books. Dewey, J. (1930/1999). Individualism old and new. Amherst, NY: Prometheus Books.

Dewey, J. (1939/1989). Freedom and culture. Amherst, NY: Prometheus Books.

eMarketer. (2016). Growth in time spent with media is slowing. Retrieved on July 14, 2018 from https://www.emarketer.com/Article/Growth-Time-Spent-with-MediaSlowing/1014042

Gallup. (2016). Americans trust in mass media sinks to new low. Retrieved on July 3, 2018 from https://news.gallup.com/poll/195542/americans-trust-mass-media-sinksnew-low.aspx

Hart, R. P. (1994). Seducing America: How television charms the modern voter. New York, NY: Oxford University Press.

Jansen, S. C. (2012). Walter Lippmann: A critical introduction to media and communication theory. New York, NY: Peter Lang.

Lippmann, W. (1922/2010). Public opinion. Blacksburg, VA: Wilder Publications.

Lippmann, W. (1925/1993). The phantom public. New Brunswick, NJ: Transaction Publishers.

Mason, L. E. (2016). Cultivating civic habits: A Deweyan analysis of the National Council for the Social Studies position statement on guidelines for social studies teaching and learning. Education \& Culture: The Journal of the John Dewey Society, 32(1), 87-110.

Mason, L. E. (2017). The significance of Democracy and Education for $21^{\text {st }}$ century education. Education \& Culture: The Journal of the John Dewey Society, 33(1), 4157.

Oreskes, N., \& Conway, E. M. (2010). Merchants of doubt: How a handful of scientists obscured the truth on issues from tobacco smoke to global warming. London, UK: Bloomsbury Press.

Pew Research Center. (2018). Teens, social media \& technology 2018. Retrieved on April 29, 2018 from www.pewresearch.org

Postman, N., \& Powers, S. (2008). How to watch TV news, revised edition. New York, NY: Penguin Books.

Taibbi, M. (2019). Hate Inc: Why today's media makes us despise one another. OR Books. 